\title{
Dynamic responses of bridge substructures subjected to high-speed trains
}

Kongsak Pugasap PhD, P.E., S.E.

Senior Bridge Engineer, International Engineering Consultant Co., Ltd., Klongtoey-Nua, Wattana, Bangkok, Thailand; Formerly Supervising Bridge

Engineer, WSP USA, Oakland, CA, USA (kongsak.pu@iec-thailand.com)

The substructures of high-speed rail (HSR) structures are typically rigid, as they are designed to meet stringent longitudinal displacement limits specified in most HSR design standards. For site conditions such as deep valleys and soft soils, tall columns or low foundation stiffness can lead to a flexible substructure system. Flexible substructures are preferred for bridges in seismic areas because their lower horizontal frequencies yield smaller seismic forces. This cost-effective design strategy is recognised in the California HSR design criteria manual, which specifies larger relative longitudinal displacement limits. In this work, the influences of substructure flexibility on relative displacements were investigated through dynamic analyses of 36 different numerical models representing a 20-span viaduct supported by substructures with first horizontal frequencies of $0.566-3.706 \mathrm{~Hz}$. Four key parameters were investigated: column height, span length, bearing plan layout and ratio of depth to span length. Train models from BS EN 1991-2:2003 were used as dynamic moving loads. The results of this study show that the chances of dynamic responses larger than design limits do exist as the stiffness of substructures departs from being rigid, where resonance effects on substructures are the main contributor to response amplification.

\section{Introduction}

High-speed rail (HSR) substructures are typically rigid, as they are designed to meet stringent longitudinal displacement limits specified in most HSR design standards. BS EN 1991-2:2003 (BSI, 2003) and UIC 776-2 (UIC, 2009) limit relative longitudinal displacements between two consecutive decks to $5 \mathrm{~mm}$ due to traction and braking actions and to $10 \mathrm{~mm}$ due to vertical traffic actions without consideration of the track-structure interaction. The Chinese high-speed railway design code (NRA, 2015) limits longitudinal displacements by specifying a minimum substructure stiffness. The commonly used pier cross-section supporting short-span HSR structures in China is a robust twin $6.8 \mathrm{~m} \times 3-4 \mathrm{~m}$ hollow rectangular section for height up to $12 \mathrm{~m}$ (Yan et al., 2015). The minimum substructure stiffness of the Chinese code is equivalent to limiting relative longitudinal displacements to $4 \mathrm{~mm}$ due to braking actions (He et al., 2017). The design specifications for HSR in Taiwan, China (THSR, 2005) limit relative longitudinal displacements between two consecutive decks to $7 \mathrm{~mm}$ due to a combination of traction, braking and vertical traffic actions and to $25 \mathrm{~mm}$ due to a combination of braking and vertical traffic actions of one train and an operational-level earthquake. Luo and Miyamoto (2008) developed a code-type provision using a method called spectral intensity for Japanese design standards, which requires that the stiffness of substructures be adequately provided to safeguard against train derailment during an earthquake.

Flexible substructures may not be avoided for structures crossing site conditions such as deep valleys and soft soils. Dias et al. (2008) performed vehicle-track-structure interaction analyses for a $1209 \mathrm{~m}$ continuous viaduct crossing a deep valley with a maximum pier height of more than $93 \mathrm{~m}$, a span length of $63.5 \mathrm{~m}$ and first transverse natural frequency of $0.29 \mathrm{~Hz}$. They evaluated the effects of an eccentric vertical dynamic moving train at a speed of $111 \mathrm{~m} / \mathrm{s}$, track alignment irregularities and hunting oscillations on passenger comfort. A maximum train body lateral acceleration of less than $1 \mathrm{~m} / \mathrm{s}^{2}$ was reported. A similar study with consideration of rolling contact between wheels and rails was performed by Goicolea and Antolin (2011) for the same $1209 \mathrm{~m}$ long viaduct. Vehicle-track-structure interaction analyses were carried out for train speeds of 69,83 and $97 \mathrm{~m} / \mathrm{s}$. A maximum train body lateral acceleration of less than $0.5 \mathrm{~m} / \mathrm{s}^{2}$ was reported for a train speed of $97 \mathrm{~m} / \mathrm{s}$. Another study considering rolling contact was performed by Antolin et al. (2011) for a $1176 \mathrm{~m}$ continuous viaduct crossing a deep valley with a $98 \mathrm{~m}$ pier height and $67 \mathrm{~m}$ span length. Vehicle-track-structure interaction analyses were carried out for train speeds of 56 and $97 \mathrm{~m} / \mathrm{s}$. Maximum train body lateral accelerations of less than 0.4 and $0.6 \mathrm{~m} / \mathrm{s}^{2}$ were reported for train speeds of 56 and $97 \mathrm{~m} / \mathrm{s}$, respectively. Domenech et al. (2015) performed parametric studies to investigate the effects of supporting softto-stiff soil with shear wave velocities of $80-365 \mathrm{~m} / \mathrm{s}$ on the vertical dynamic responses of $12.5-25 \mathrm{~m}$ simply supported bridges due to dynamically moving trains with speeds of $40-100 \mathrm{~m} / \mathrm{s}$. The investigation included resonance-induced vertical responses at the critical speed and resonancesuppressed vertical responses at the cancellation speed. The vertical responses of bridges supported by stiffer soil were 
closer to those supported by rigid boundary conditions. For bridges supported by softer soil, deck accelerations were lower and the critical and cancellation speeds were shifted.

Flexible substructures are preferred for bridges in seismic areas because their lower horizontal natural frequencies yield smaller seismic forces. This cost-effective design strategy is recognised in the California HSR design criteria (CHSRA, 2016), in which larger relative longitudinal displacement limits of $13 \mathrm{~mm}$ due to a combination of traction, braking and vertical traffic actions and of $57 \mathrm{~mm}$ due to a combination of braking and vertical traffic actions of one train and an operationallevel earthquake are specified for the design of HSR structures carrying ballasted tracks. For non-ballasted tracks, the limits are $18 \mathrm{~mm}$ and $59 \mathrm{~mm}$, respectively.

In the work reported in this paper, the influences of substructure flexibility on relative longitudinal displacements, relative rotations and relative vertical displacements between two consecutive decks were investigated through dynamic analyses of 36 different numerical models representing a 20 -span viaduct supported by substructures with first horizontal natural frequencies of $0.566-3.706 \mathrm{~Hz}$. Four key parameters were investigated: column height, span length, bearing plan layout and ratio of depth to span length. The results of this study revealed that, as the stiffness of the substructure departs from being rigid, the relative longitudinal displacements, relative rotations and relative vertical displacements typically used for design purposes can be influenced by the dynamic responses of substructures to a level exceeding design limits and resonance effects on substructures can be of significant concern.

\section{Parameters influencing dynamic responses}

This section discusses substructure parameters and other key parameters that ultimately influence the relative displacements and rotations between two consecutive decks. Analogous to vertical and torsional natural frequencies being important parameters for the dynamic responses of superstructures, horizontal natural frequencies are identified as important parameters that can affect the dynamic responses of substructures and subsequently impact relative displacements and rotations. Horizontal natural frequencies are also recognised as one of the most important parameters in the seismic design of bridge substructures.

In the author's experience, bridge geometry parameters that are deemed to be associated with horizontal natural frequencies and influence relative displacements and rotations between two consecutive decks are the column height, span length (pier spacing), bearing plan layout and depth to span length ratio. These four parameters and their relationship with relative displacements are graphically described using an exaggerated bridge in Figure 1. The column height has an inverse relationship with the horizontal stiffness and frequencies. The span length has a direct relationship with the superstructure mass, inversely related to the horizontal frequencies. The bearing plan layout may not have a clear connection with the horizontal frequencies, however, as shown schematically in Figures 2 (a) and 2(b), with different bearing longitudinal layouts but identical substructure deformations, this parameter has a direct relationship with relative displacements between consecutive decks, particularly in the vertical direction. The girder depth may not have a clear connection with the horizontal frequencies, but the product of this parameter and girder end rotations about bearings directly translates to displacements at the top deck corner.

The ranges of parameters used in this study were selected from the author's experience of reviewing the final design drawings of most HSR structures in California. Columns of diameter $2.45 \mathrm{~m}$ and height of $6-8 \mathrm{~m}$ were often considered, although the same column size with height up to $12.5 \mathrm{~m}$ was also found. More than $70 \%$ of designs used span lengths of 26-38 $\mathrm{m}$. The distances between the centreline of bearings to the centreline of piers were often $2.0-2.5 \mathrm{~m}$ and $0.75-1.25 \mathrm{~m}$

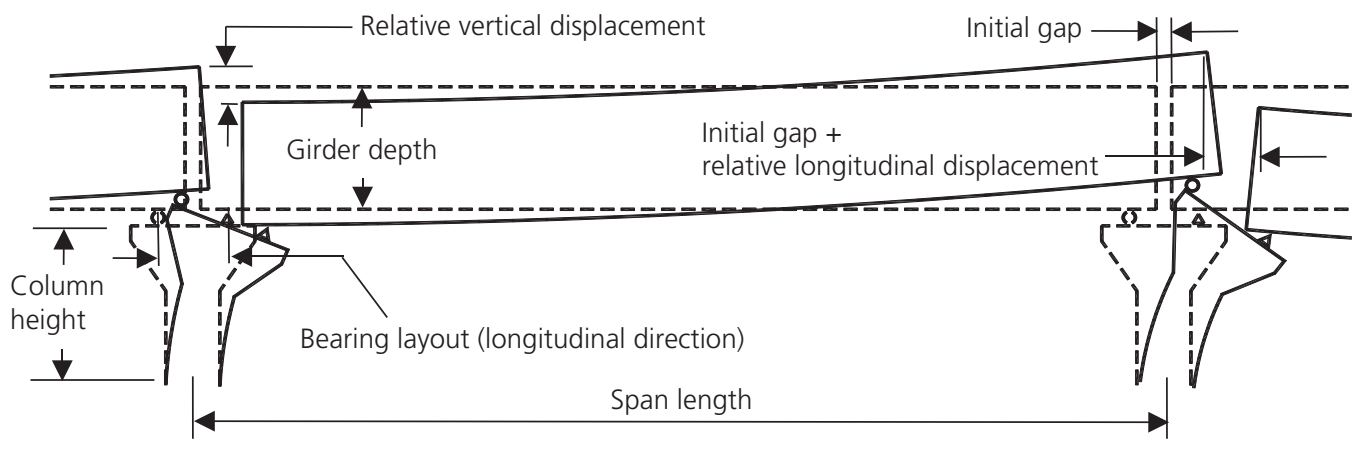

Figure 1. Graphical description of the four studied parameters and relative displacements 


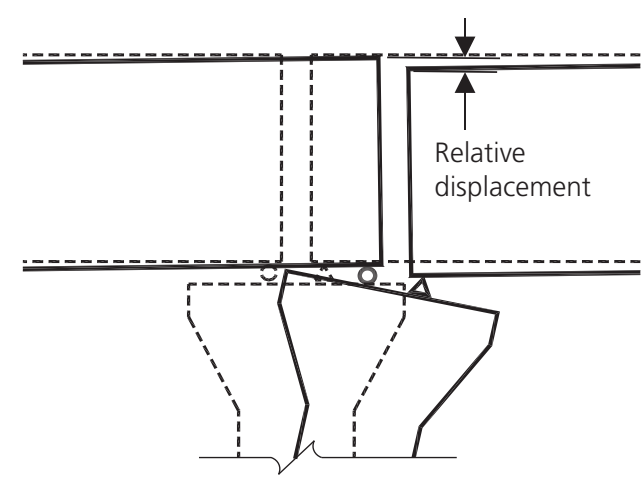

(a)

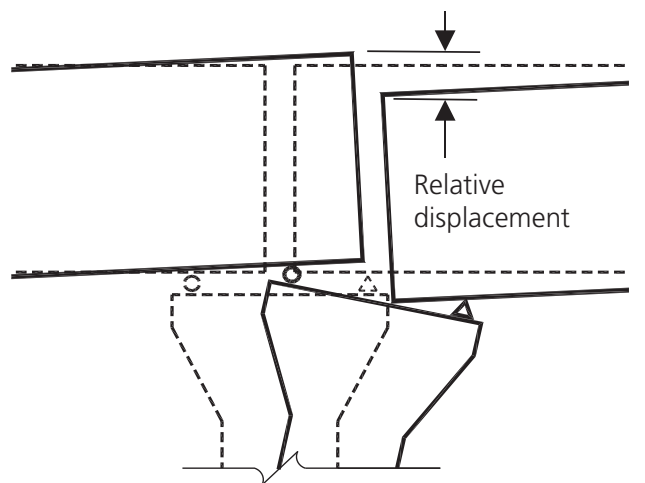

(b)

Figure 2. Effects of bearing longitudinal layout on relative displacement: (a) narrow bearing layout; (b) wider bearing layout

for transverse and longitudinal directions, respectively, translating to the use of bearing plan layouts between $4 \mathrm{~m} \times 1.5 \mathrm{~m}$ and $5 \mathrm{~m} \times 2.5 \mathrm{~m}$ (transverse $\times$ longitudinal) in this study. A broad range of depth to span ratios (1/12 to $1 / 8)$ was chosen for this research.

Dynamic responses due to only vertical traffic action were studied because the condition resulting from this action represents the most frequent state that always occurs in every single passage of trains on structures. Longitudinal actions (e.g. traction, braking, earthquake action) were not included in the scope of this study.

\section{Numerical models}

Numerical models were developed using CSiBridge (CSI, 2017). As shown in Figure 3, each numerical model represented a 20-span successive simply supported viaduct supported by two abutments at each end and 19 single columns in between. The bearing articulation of each span was a pin and roller along the $X$ axis (i.e. longitudinal axis). The $Y$ and $Z$ axes represent transverse and vertical axes, respectively. The structure is level, straight and square.
In total, 36 numerical models were developed. Table 1 lists the different combinations of three different column heights, three different span lengths, two different bearing layouts and two different depth/span ratios for models 1-14 and models 35 and 36. Although not shown in Table 1, models 15-24 had the same parameters as models $3-12$, but the column height was $8 \mathrm{~m}$ rather than $6 \mathrm{~m}$. Similarly, models 25-34 had the same parameters as models $1-10$, but the column height was $12.5 \mathrm{~m}$ rather than $6 \mathrm{~m}$.

Frame elements were used to model the girders, each sub-divided into 12 equal-length elements. 12 different girder properties arose from the combination of three span lengths, two bearing layouts and two depth/span ratios. As the aim of this work was to study substructures, the properties of the 12 girders were selected to enhance rigidity in order to minimise resonance effects from superstructures; their vertical frequencies thus aligned with the values recommended by the California HSR design criteria (CHSRA, 2016); see Figure 4. The upper and lower vertical frequency limits of BS EN 1991-2:2003 (BSI, 2003) are also shown in Figure 4 for comparative purposes. Thus, the resulting static mid-span

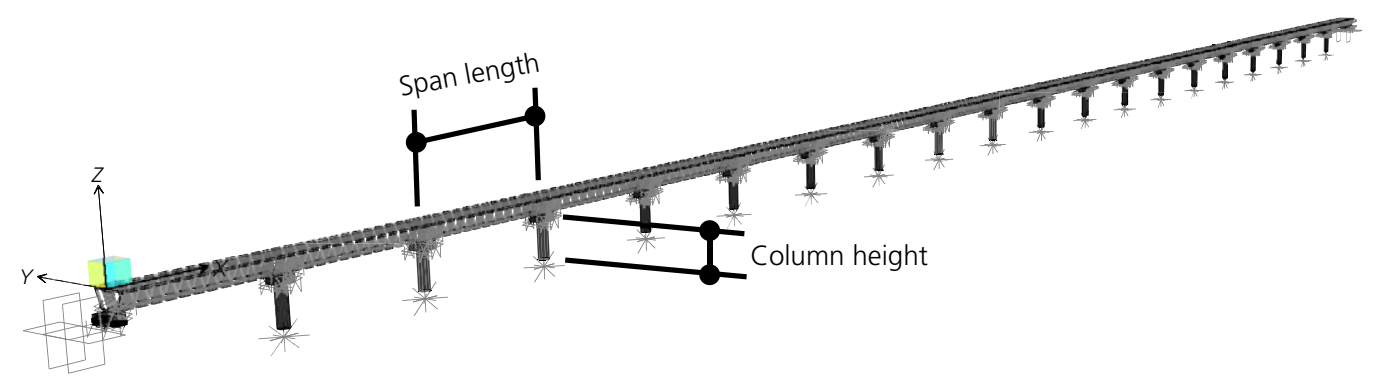

Figure 3. CSiBridge numerical model 


\begin{tabular}{|c|c|c|c|c|c|c|c|c|c|c|c|c|c|c|c|c|c|}
\hline \multirow[b]{2}{*}{ Parameter } & \multicolumn{17}{|c|}{ Model } \\
\hline & 1 & 2 & 3 & 4 & 5 & 6 & 7 & 8 & 9 & 10 & 11 & 12 & 13 & 14 & & 35 & 36 \\
\hline \multicolumn{18}{|c|}{ Column height: $m$} \\
\hline 6 & $\checkmark$ & $\checkmark$ & $\checkmark$ & $\checkmark$ & $\checkmark$ & $\checkmark$ & $\checkmark$ & $\checkmark$ & $\checkmark$ & $\checkmark$ & $\checkmark$ & $\checkmark$ & & & $\ldots$ & & \\
\hline 8 & & & & & & & & & & & & & $\checkmark$ & $\checkmark$ & $\ldots$ & & \\
\hline 12.5 & & & & & & & & & & & & & & & $\ldots$ & $\checkmark$ & 2 \\
\hline \multicolumn{18}{|c|}{ Span length: m } \\
\hline 26 & $\checkmark$ & $\checkmark$ & $\checkmark$ & $\checkmark$ & & & & & & & & & $\checkmark$ & $\checkmark$ & $\ldots$ & & \\
\hline 32 & & & & & $\checkmark$ & $\checkmark$ & $\checkmark$ & $\checkmark$ & & & & & & & $\ldots$ & & \\
\hline 38 & & & & & & & & & $\checkmark$ & $\checkmark$ & $\checkmark$ & $\checkmark$ & & & $\ldots$ & $\checkmark$ & $\checkmark$ \\
\hline \multicolumn{18}{|c|}{ Bearing layout: $m$} \\
\hline $4 \times 1.5$ & $\checkmark$ & $\checkmark$ & & & $\checkmark$ & $\checkmark$ & & & $\checkmark$ & $\checkmark$ & & & $\checkmark$ & $\checkmark$ & $\ldots$ & & \\
\hline $5 \times 2.5$ & & & $\checkmark$ & $\checkmark$ & & & $\checkmark$ & $\checkmark$ & & & $\checkmark$ & $\checkmark$ & & & $\ldots$ & $\checkmark$ & $\checkmark$ \\
\hline \multicolumn{18}{|c|}{ Depth/span ratio } \\
\hline $1 / 12$ & & $\checkmark$ & & $\checkmark$ & & $\checkmark$ & & $\checkmark$ & & $\checkmark$ & & $\checkmark$ & & $\checkmark$ & $\ldots$ & & $\checkmark$ \\
\hline $1 / 8$ & $\checkmark$ & & $\checkmark$ & & $\checkmark$ & & $\checkmark$ & & $\checkmark$ & & $\checkmark$ & & $\checkmark$ & & $\ldots$ & $\checkmark$ & \\
\hline
\end{tabular}

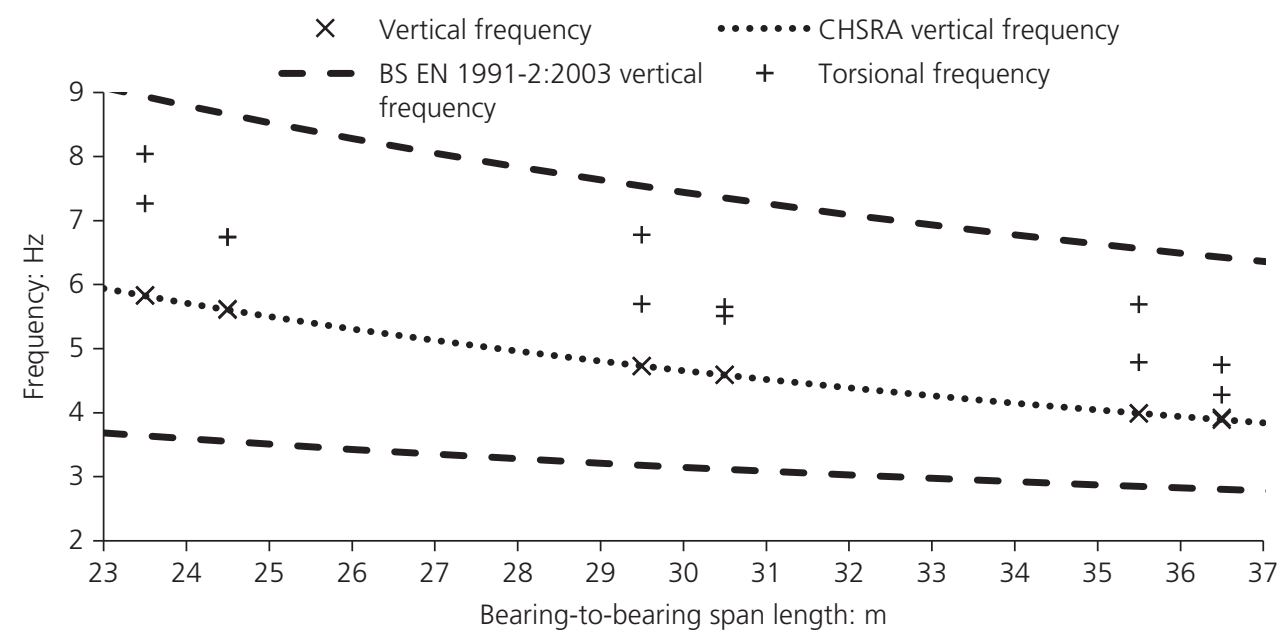

Figure 4. Dynamic properties of 12 girders

deflections were as low as $L / 4000$ to $L / 3000$ when subjected to two CHSRA E-50 loads plus impact loads (comparable to two BS EN 1991-2:2003 LM71 load models plus impact loads). Although not directly relevant, the torsional frequencies of the 12 girders are also shown in Figure 4. Spring elements were used to model the bearings, with a vertical stiffness of $1750 \mathrm{MN} / \mathrm{m}$. The transverse frequencies of the 12 girders were several times greater than their vertical frequencies.

Frame elements were used to model the columns, with each sub-divided into four. Although a column diameter of $2.45 \mathrm{~m}$ was used for the column sectional properties of all 36 numerical models, 36 different horizontal dynamic properties were generated from three different heights, 12 different superstructure masses and different boundary conditions at the column base. A fixed boundary condition at the $6 \mathrm{~m}$ and $8 \mathrm{~m}$ column bases was used as the upper bound and foundation stiffness at the $12.5 \mathrm{~m}$ column base was used as the lower bound. A single $3 \mathrm{~m}$ dia. drilled shaft with $20 \mathrm{~m}$ embedment in medium-dense to dense sand with a unit weight of $18.85 \mathrm{kN} / \mathrm{m}^{3}$, a friction angle of $35^{\circ}$ and $p-y$ modulus of $190 \mathrm{MN} / \mathrm{m}^{3}$ was assumed for developing the foundation stiffness using LPile. For all the 36 numerical models, the first longitudinal frequencies were in the range $0.811-3.706 \mathrm{~Hz}$ and the first transverse frequencies were $0.566-2.456 \mathrm{~Hz}$. Shortheight, rigid sectional properties and fixed boundary conditions were used to model the abutments. 
Rigid links were used to connect the top of each column with the bottoms of four bearings located according to the bearing layout parameter. The girder depth was considered in the analyses by locating the pivot points where the bottom of the girders and the top of the bearings met, as well as positioning the girder elements at their centre of gravity above the top of the bearings. A girder centre of gravity from the soffit of approximately 0.63 times the girder depth was used.

Train models HSLM-A1 to HSLM-A10 of BS EN 19912:2003 (BSI, 2003) were used as dynamically moving loads with speeds varying in the range $40-110 \mathrm{~m} / \mathrm{s}$ in $5 \mathrm{~m} / \mathrm{s}$ intervals. For each numerical model, time-history direct integration analyses were performed for ten different trains running at 15 different speeds in the forward direction (positive direction of the $X$ axis) on one track with a $2.515 \mathrm{~m}$ eccentric path from the longitudinal axis. A time step of $0.025 \mathrm{~s}$ was used. The duration for each analysis was set to allow the full length of trains to pass the entire length of the structure. Rayleigh damping of $1 \%$ was used.

Rails and non-linear track resistances were not included in the numerical models, but were identified as an item for future study. Nevertheless, smaller dynamic responses are anticipated if track-structure interaction is considered.

\section{Results and discussion}

This section summarises and discusses the results obtained from the 36 numerical models for measurements at the top of the girders. Absolute maximum and minimum relative longitudinal displacements, relative rotations about the longitudinal axis and relative vertical displacements were outputted and enveloped from all 19 expansion joints of each numerical model. The total number of outputs for each of the three result types was 10800 (two envelopes $\times 36$ numerical models $\times$ ten train models $\times 15$ speeds). The results were compared with the design limits given in UIC 776-2 (UIC, 2009) and BS EN 1991-2:2003 (BSI, 2003), as these codes provide the most comprehensive suite of HSR load models for dynamic analysis purposes, have been extensively used and validated in many countries for decades and served as a basis for the development of recent HSR codes, including the California HSR design criteria (CHSRA, 2016).

\subsection{Relative longitudinal displacements}

Most HSR design standards require that relative longitudinal displacements between two consecutive decks be controlled because excessive displacements can lead to rail over-stresses or ballast de-stabilisation. Table 2 summarises the mean, median, maximum and minimum of the 10800 outputs, each classified by three different column heights, three different span lengths, two bearing layouts and two girder depth/span ratios (e.g. 3600 outputs for each column height). It was
Table 2. Statistical summary of relative longitudinal displacements classified by column height, span length, bearing layout and depth/span ratio

\begin{tabular}{|c|c|c|c|c|}
\hline \multirow[b]{2}{*}{ Parameter } & \multicolumn{4}{|c|}{ Relative longitudinal displacement: $\mathrm{mm}$} \\
\hline & Mean & Median & Maximum & Minimum \\
\hline \multicolumn{5}{|c|}{ Column height: $m$} \\
\hline 6 & 1.28 & 0.96 & 14.47 & 0.23 \\
\hline 8 & 2.12 & 1.61 & 23.19 & 0.46 \\
\hline 12.5 & 5.92 & 5.40 & 17.98 & 1.37 \\
\hline \multicolumn{5}{|c|}{ Span length: m } \\
\hline 26 & 2.42 & 1.73 & 14.49 & 0.23 \\
\hline 32 & 3.18 & 2.06 & 20.43 & 0.34 \\
\hline 38 & 3.72 & 2.05 & 23.19 & 0.39 \\
\hline \multicolumn{5}{|c|}{ Bearing layout: m } \\
\hline $4 \times 1.5$ & 2.46 & 1.58 & 12.80 & 0.23 \\
\hline $5 \times 2.5$ & 3.76 & 2.29 & 23.19 & 0.40 \\
\hline \multicolumn{5}{|c|}{ Depth/span ratio } \\
\hline $1 / 12$ & 3.04 & 1.88 & 20.43 & 0.23 \\
\hline $1 / 8$ & 3.17 & 1.96 & 23.19 & 0.24 \\
\hline
\end{tabular}

observed that every mean, median and minimum of the outputs classified by all four parameters, except for the median classified by span length, were greater as the magnitudes of the parameters increased. The most sensitive parameter was found to be column height and the least sensitive the girder depth/span ratio.

Train model and speed parameters were investigated in a similar manner. The mean, maximum and minimum of outputs classified by train model generally increased from model HSLM-A1 to HSLM-A10, except for the maximum outputs spiking for HSLM-A3 and HSLM-A6 with magnitudes greater than $20 \mathrm{~mm}$. For outputs classified by train speed, the mean, maximum and minimum values were generally greater for train speeds of $45-80 \mathrm{~m} / \mathrm{s}$.

Of the total 10800 outputs, 376 (3.48\%) exceeded the UIC/BSI (BSI, 2003; UIC, 2009) design limit of $10 \mathrm{~mm}$ due to vertical train load. A stacked histogram of the 376 outputs classified by column height is presented in Figure 5. The vertical axis represents the frequency of outputs within a $0.2 \mathrm{~mm}$ bin and the horizontal axis represents the relative longitudinal displacements. It was observed that the frequency of outputs exceeding $10 \mathrm{~mm}$ was higher with an increase in column height. Figure 6 shows a stacked histogram of the 376 outputs classified by span length. Although not as apparent as the outputs classified by column height, the frequency of outputs exceeding $10 \mathrm{~mm}$ was generally higher with an increase in span length. A stacked histogram of the 376 outputs classified by bearing layout is shown in Figure 7: the frequency of outputs exceeding $10 \mathrm{~mm}$ was higher for a larger bearing layout. 


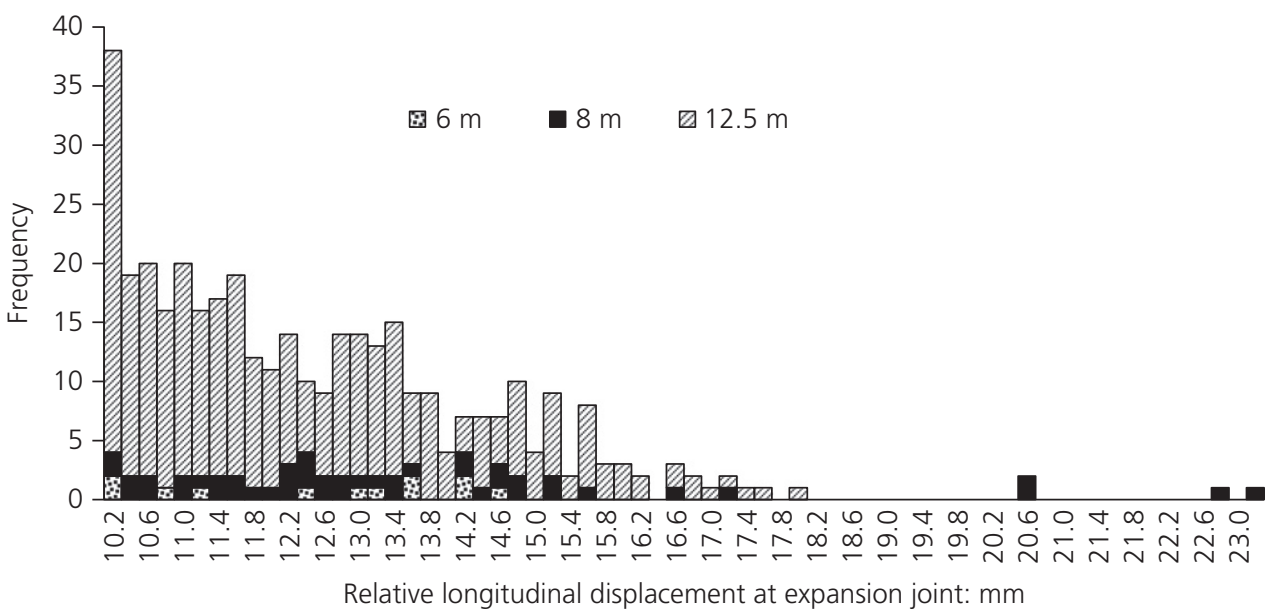

Figure 5. Histogram of relative longitudinal displacements $(\geq 10 \mathrm{~mm})$ classified by column height

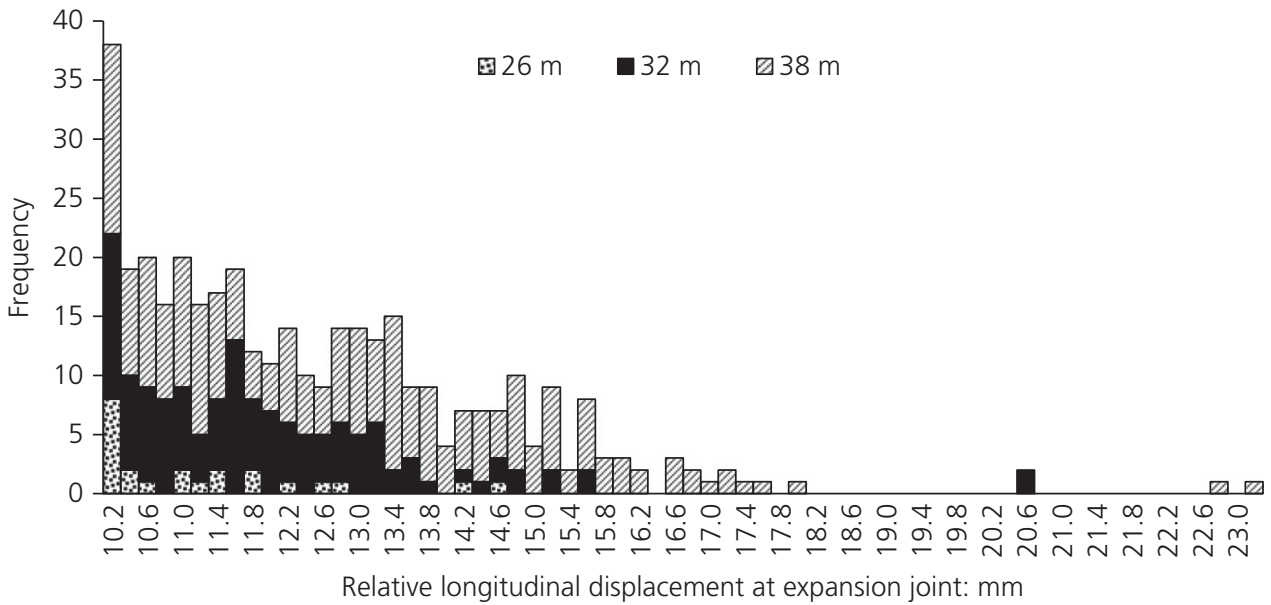

Figure 6. Histogram of relative longitudinal displacements $(\geq 10 \mathrm{~mm})$ classified by span length

The girder depth/span ratio was the least sensitive parameter for outputs exceeding $10 \mathrm{~mm}$. There were 203 and 173 outputs for depth/span ratios of $1 / 12$ and $1 / 8$, respectively, while outputs greater than $20 \mathrm{~mm}$ were found for both ratios.

The 376 outputs exceeding the UIC/BSI design limit classified by train model and speed were investigated in a similar manner. Due to the similarity of the frequency distributions, no useful remarks besides those already discussed above could be made for outputs classified by the train model. For the outputs classified by train speed, stacked histograms with the arrangement in Figures 5-7 provide no meaningful insight. Therefore, a rearrangement was made and the results are presented in Figure 8, where the vertical axis represents the frequency of outputs for each train speed, the horizontal axis represents train speed and each column is stacked with outputs of bins of $10-13,13-16,16-19,19-22$ and $22-25 \mathrm{~mm}$. It was observed that the high frequency of outputs exceeding $10 \mathrm{~mm}$ was within the $45-80 \mathrm{~m} / \mathrm{s}$ range and the largest outputs occurred for a train speed of $45 \mathrm{~m} / \mathrm{s}$.

The relationship between the maximum outputs from the 36 numerical models and their dynamic characteristics was investigated. The maximum outputs were plotted against the column's first longitudinal frequency and then classified by the two most sensitive parameters (i.e. column height and bearing 


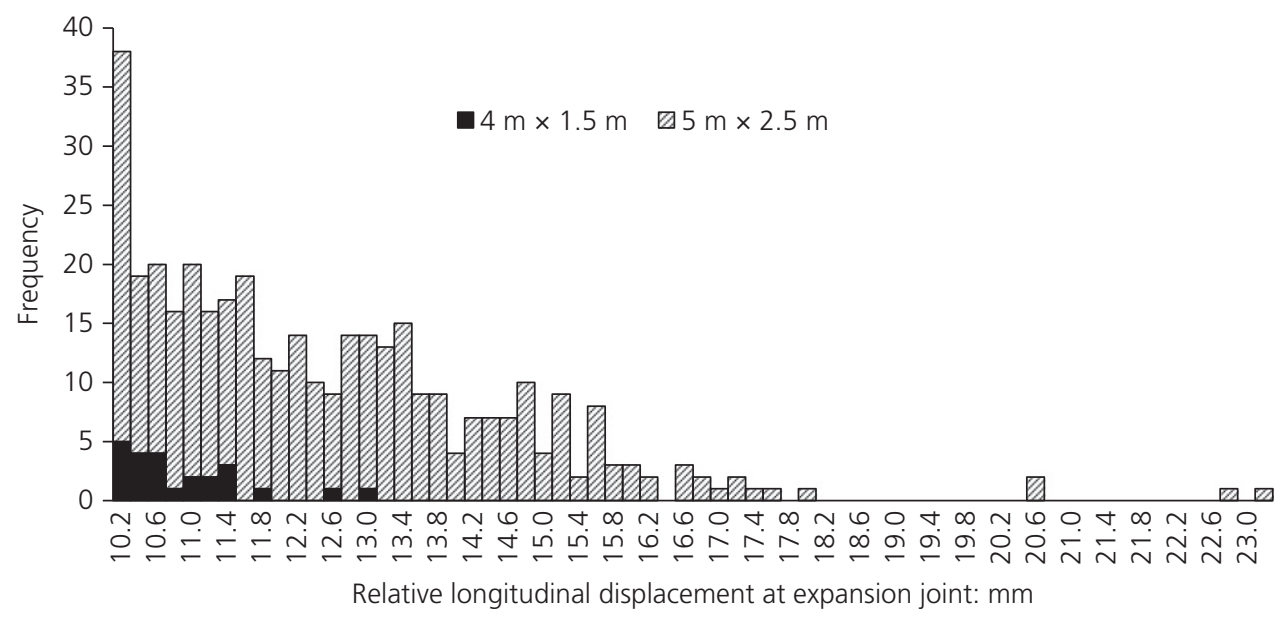

Figure 7. Histogram of relative longitudinal displacements $(\geq 10 \mathrm{~mm})$ classified by bearing layout

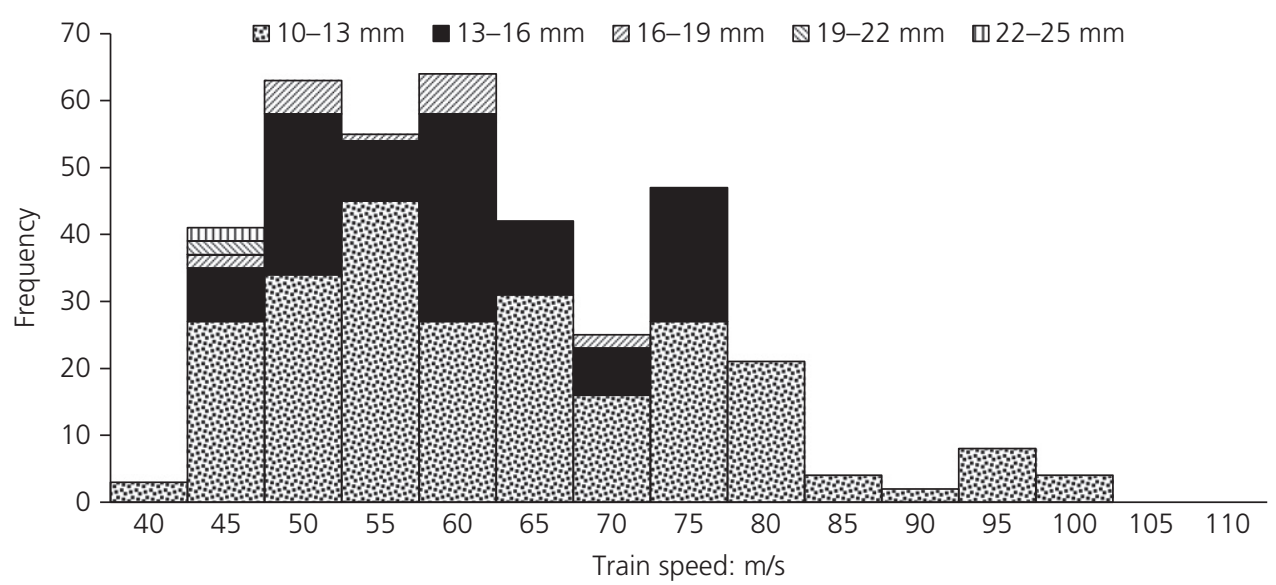

Figure 8. Histogram of relative longitudinal displacements $(\geq 10 \mathrm{~mm})$ classified by train speed

layout), as shown in Figure 9. The following points can be made.

- Resonance effects from near to exact match between the column's first longitudinal frequencies and the ratios of resonant speed to critical coach length - hereafter referred to as frequencies at critical train characteristics - were the main contributor leading to large maximum outputs for the models with column heights of $6 \mathrm{~m}$ and $8 \mathrm{~m}$. In this study, frequencies at critical train characteristics ranged from $40 \mathrm{~m} / \mathrm{s}$ minimum train speed over a $27 \mathrm{~m}$ maximum coach length $(1.481 \mathrm{~Hz})$ to $110 \mathrm{~m} / \mathrm{s}$ maximum train speed over a $18 \mathrm{~m}$ minimum coach length $(6.111 \mathrm{~Hz})$.

- Since the range of the column's first longitudinal frequencies for the $12.5 \mathrm{~m}$ column height models is outside the range of frequencies at critical train characteristics, their maximum outputs were not influenced by resonance effects, but by low substructure longitudinal stiffness.

- Lower longitudinal frequencies generally yielded larger maximum outputs, but maximum outputs for higher longitudinal frequencies could be magnified by resonance effects.

- A longer longitudinal bearing layout yielded maximum outputs larger than those for a shorter longitudinal bearing layout.

The condition leading to large relative longitudinal displacements, especially those greater than $20 \mathrm{~mm}$, was found for models 20 and 23. Under this condition, the column's first longitudinal frequencies $(2.26 \mathrm{~Hz}$ for model 20 and $1.968 \mathrm{~Hz}$ 


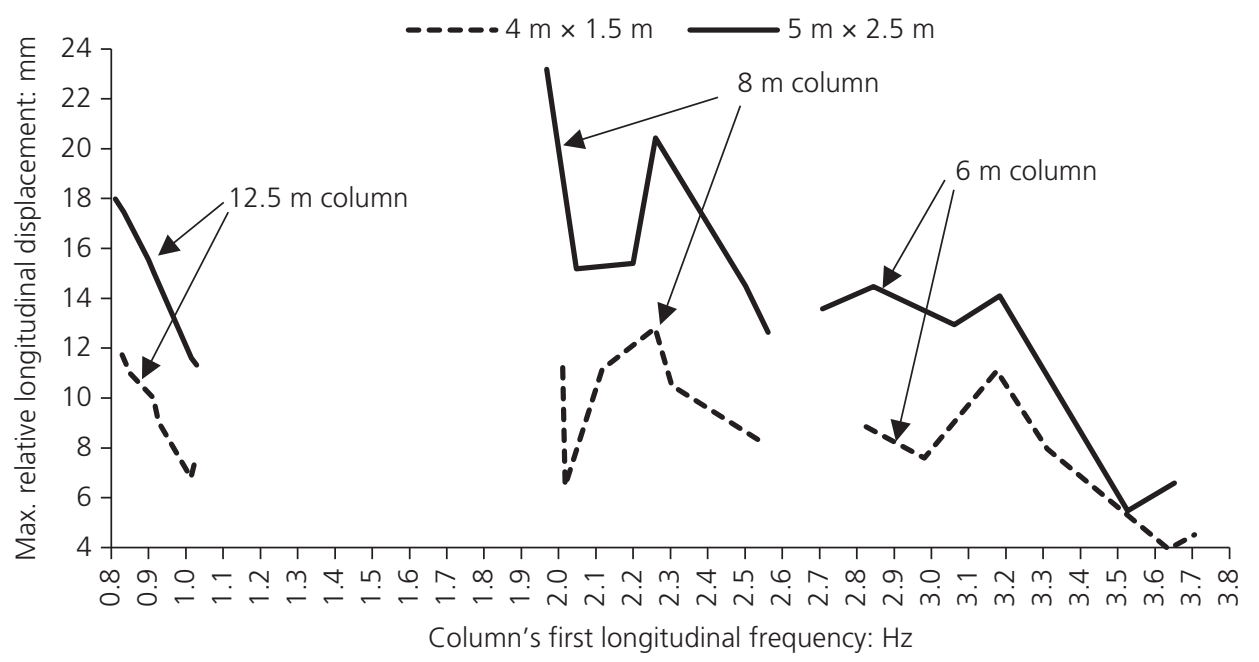

Figure 9. Maximum relative longitudinal displacement plotted against column first longitudinal frequency classified by column height and bearing layout

for model 23) nearly matched the frequencies at the critical train characteristics $(=2.25 \mathrm{~Hz}$ for $45 \mathrm{~m} / \mathrm{s}$ train speed over $20 \mathrm{~m}$ HSLM-A3 coach length for model 20 and $1.957 \mathrm{~Hz}$ for $45 \mathrm{~m} / \mathrm{s}$ train speed over $23 \mathrm{~m}$ HSLM-A6 coach length for model 23). Time-history longitudinal displacements of model 23 subjected to HSLM-A6 with a speed of $45 \mathrm{~m} / \mathrm{s}$ are presented in Figure 10 for both girder top ends (points A and B). The largest relative longitudinal displacement of model 23 was a result of point $\mathrm{B}$ moving forwards with a longitudinal displacement of $12.4 \mathrm{~mm}$ and point A moving backwards with a longitudinal displacement of $10.8 \mathrm{~mm}$ at $24.825 \mathrm{~s}$. Due to different train arrival times at each column, resonance effects on the columns occurred with different timing, resulting in a phase difference between the longitudinal displacements of adjacent columns. Note that each girder was pinned on one of the two columns, so it moved longitudinally with such a column. As also shown in Figure 10, the phase difference between the displacements of points $\mathrm{A}$ and $\mathrm{B}$ grew as the resonance effects on columns developed from a repeated number of coaches passing over. The deformed geometry at $24.825 \mathrm{~s}$ with the associated HSLM-A6 position where the last two coaches are about to leave the last span is shown in Figure 11.

Additional analyses were performed of model 23 subjected to a static LM71 (BSI, 2003) plus an impact factor of 1.105 on two tracks of the last span and a static HSLM-A6 with the same train position shown in Figure 11. Note that the two

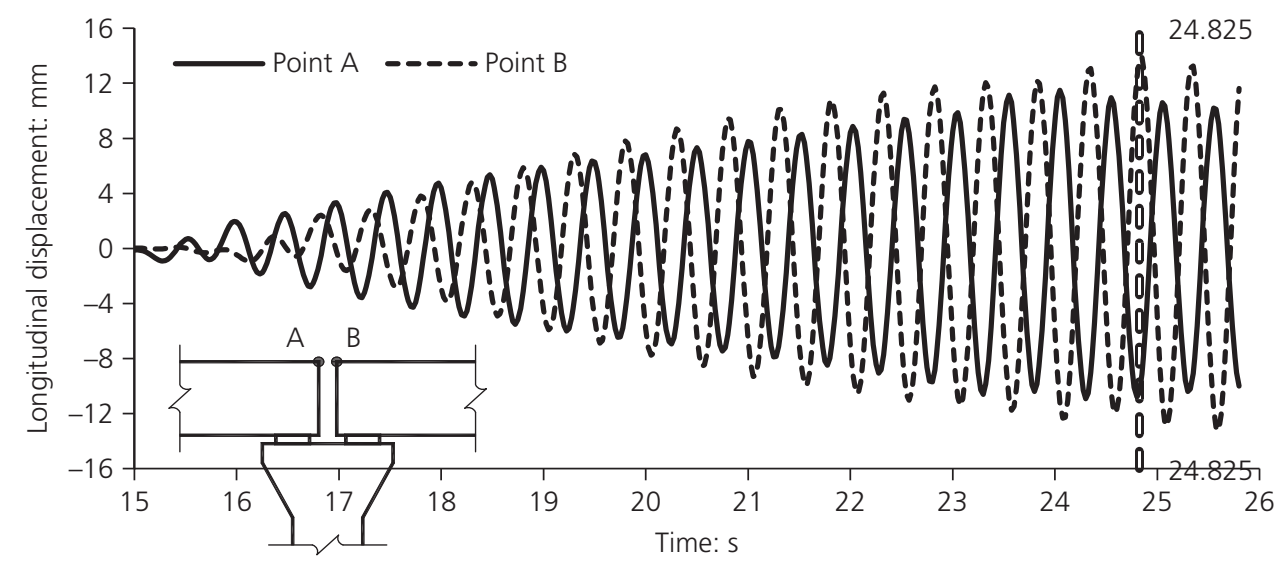

Figure 10. Time-history longitudinal displacements of model 23 


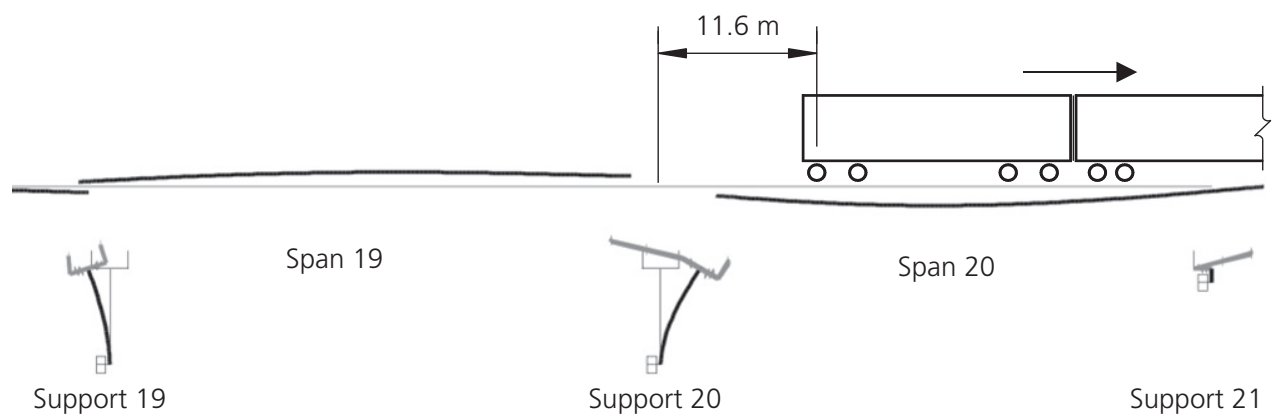

Figure 11. Deformed geometry of model 23 at $24.825 \mathrm{~s}$

Table 3. Summary of static and dynamic responses of model 23

\begin{tabular}{|c|c|c|c|c|}
\hline Response & $\begin{array}{c}2 \times \text { LM71 on } \\
\text { span } 20\end{array}$ & $\begin{array}{l}\text { Static HSLM-A6 } \\
\text { with train position } \\
\text { at } 24.825 \mathrm{~s}\end{array}$ & $\begin{array}{l}\text { Dynamic } \\
\text { HSLM-A6 at } \\
24.825 \mathrm{~s}\end{array}$ & $\begin{array}{c}\text { HSLM-A6 } \\
\text { dynamic/static } \\
\text { ratio }\end{array}$ \\
\hline Relative longitudinal displacement over support 20: mm & 6.35 & 0.76 & 23.19 & 30.51 \\
\hline Longitudinal displacement at top of column 20: mm & 2.86 & 0.29 & 11.95 & 41.21 \\
\hline Rotation about transverse axis at top of column 20: mrad & 0.60 & 0.06 & 2.13 & 35.50 \\
\hline Mid-span deflection of span 20: mm & 9.11 & 1.22 & 3.18 & 2.61 \\
\hline Reaction of span 20 on support 20: kN & 3677.40 & 374.50 & 414.60 & 1.11 \\
\hline
\end{tabular}

LM71 load models and the $10 \mathrm{~mm}$ limit are associated by BS EN 1991-2:2003 (BSI, 2003) for design purposes. The static and dynamic responses due to these loads are summarised in Table 3. The following observations were made.

- Amplification due to resonance effects was large enough to make the dynamic responses due to the lighter HSLM-A6 surpass the static responses due to the heavier LM71 normally used for design purposes.

- Due to a robust girder vertical frequency of $3.988 \mathrm{~Hz}$, the superstructure was not subject to resonance effects, partly as evident by a low dynamic-to-static ratio of reactions. However, large cyclic longitudinal displacements and rotations about the transverse axis at top of the column along with eccentric bearing seats induced cyclic vertical displacements of the bearing seats, which in turn vibrated the superstructure at the same column's first longitudinal frequency and caused additional dynamic mid-span deflection. In this case, the dynamic responses were not large enough to surpass the static responses.

\subsection{Relative rotations about the longitudinal axis}

Excessive relative rotations about the longitudinal axis between two consecutive decks cause excessive twists of track, which need to be controlled to avoid concerns regarding passenger comfort and riding stability. Table 4 summarises the mean, median, maximum and minimum of the 10800 outputs, each
Table 4. Statistical summary of relative rotations classified by column height, span length, bearing layout and depth/span ratio

\begin{tabular}{|c|c|c|c|c|}
\hline \multirow[b]{2}{*}{ Parameter } & \multicolumn{4}{|c|}{ Relative rotation: mrad } \\
\hline & Mean & Median & Maximum & Minimum \\
\hline \multicolumn{5}{|c|}{ Column height: $\mathrm{m}$} \\
\hline 6 & 0.23 & 0.19 & 1.90 & 0.08 \\
\hline 8 & 0.23 & 0.21 & 1.95 & 0.09 \\
\hline 12.5 & 0.27 & 0.24 & 2.85 & 0.11 \\
\hline \multicolumn{5}{|c|}{ Span length: m } \\
\hline 26 & 0.20 & 0.18 & 1.08 & 0.08 \\
\hline 32 & 0.26 & 0.22 & 2.85 & 0.10 \\
\hline 38 & 0.26 & 0.23 & 1.90 & 0.11 \\
\hline \multicolumn{5}{|c|}{ Bearing layout: $m$} \\
\hline $4 \times 1.5$ & 0.30 & 0.26 & 2.85 & 0.13 \\
\hline $5 \times 2.5$ & 0.19 & 0.17 & 1.51 & 0.08 \\
\hline \multicolumn{5}{|c|}{ Depth/span ratio } \\
\hline $1 / 12$ & 0.22 & 0.19 & 1.95 & 0.08 \\
\hline $1 / 8$ & 0.26 & 0.23 & 2.85 & 0.10 \\
\hline
\end{tabular}

classified by the key parameters. The sensitivity of the mean, median and minimum of outputs for all parameters was not as apparent as for the relative longitudinal displacements. However, it was observed that the outputs were generally greater for the tallest column, the narrower transverse bearing layout and the deeper girder, collectively implying a condition of weaker geometries against twist. 
Statistical information for the 10800 outputs classified by train model is not reported here as no useful insight was found. For the 10800 outputs classified by train speed, it was found that the mean, median and maximum outputs were greater for train speeds higher than $95 \mathrm{~m} / \mathrm{s}$.

For a train speed greater than $55.6 \mathrm{~m} / \mathrm{s}$, UIC 776-2 (UIC, 2009) specifies a $1.5 \mathrm{~mm}$ limit of vertical deviation at any corner of a $1.435 \mathrm{~m}$ wide $\times 3 \mathrm{~m}$ long plane as a deck twist limit. A simplified relationship between deck twist and relative rotation was made by assuming the worst-case scenario where any axle of the same plane is about to arrive at or depart from the deck joint. Therefore, a relative rotation of $1.5 / 1.435=1.1 \mathrm{mrad}$ was assumed to be approximately the UIC 776-2 deck twist limit.

Out of the total 10800 outputs, $31(0.29 \%)$ exceeded the $1.1 \mathrm{mrad}$ limit. Out of these 31, 29 were for the narrower bearing layout, 25 for the deeper girder, 18 for a span length of $32 \mathrm{~m}$ and 18 for a column height of $12.5 \mathrm{~m}$, which also imply a condition of weaker geometries against twist. A stacked histogram of the 31 outputs classified by train speed is shown in Figure 12. The vertical axis represents the frequency of outputs for each train speed, the horizontal axis represents the train speed and each column is stacked with outputs of bins of $1.1-1.4,1.4-1.8,1.8-2.2$ and $2.6-3 \mathrm{mrad}$. It was found that the frequency of outputs exceeding $1.1 \mathrm{mrad}$ was at a train speed of $100 \mathrm{~m} / \mathrm{s}$ or more, and the largest output occurred at the highest speed.

The relationship between maximum outputs exceeding $1.1 \mathrm{mrad}$ and their dynamic characteristics was investigated. As presented in Figure 13, the maximum relative rotations were plotted against the ratio of superstructure first torsional frequency to the frequency at critical train characteristics and the ratio of span length to 1.5 times the coach length. The following points are noted.

- Detailed information for the largest maximum output of 2.85 mrad (shown by markers $\times$ and + on the far right of Figure 13) is discussed. This condition was found for model 29 subjected to HSLM-A4 with a train speed of $110 \mathrm{~m} / \mathrm{s}$ (i.e. frequency at critical train characteristics of $110 \mathrm{~m} / \mathrm{s}$ over a $21 \mathrm{~m}$ coach length equal to $5.24 \mathrm{~Hz}$ ). As the first torsional frequency of the superstructure was $5.51 \mathrm{~Hz}$, the ratio of these two frequencies was 1.05 (marker $\times$ on the far right of Figure 13). The ratio of span length to 1.5 times coach length was $32 /(1.5 \times 21)=1.02$ (marker + on the far right). The near unity of these ratios is the main contributor leading to resonance phenomena.

- For the near unity of the second kind of ratio, it was found that the train was positioned such that at every cycle of torsional oscillation, four axles fitted within one span, while two fitted within adjacent span(s), which in turn intensified the out-of-phase rotation between adjacent girders. A schematic diagram of train position is also shown in Figure 13.

- A span/coach length ratio of $i-0.5(i=1,2,3, \ldots)$ is known to be an optimal criterion to suppress resonance effects for the vertical dynamic responses of superstructures (Yang et al., 2004). The opposite outcome for torsional dynamic responses was identified as an item to be investigated in future studies.

- The influence of substructure flexibility on relative rotations was not as significant as superstructure torsional frequencies and the relationship between coach length and span.

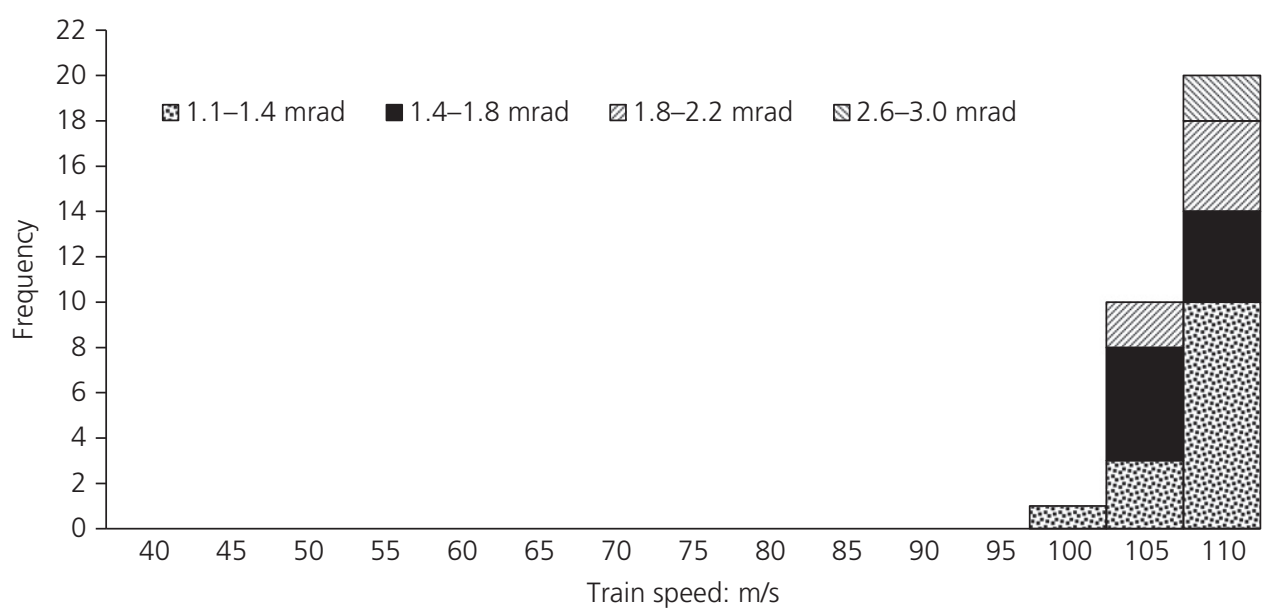

Figure 12. Histogram of relative rotations $(\geq 1.1 \mathrm{mrad})$ classified by train speed 


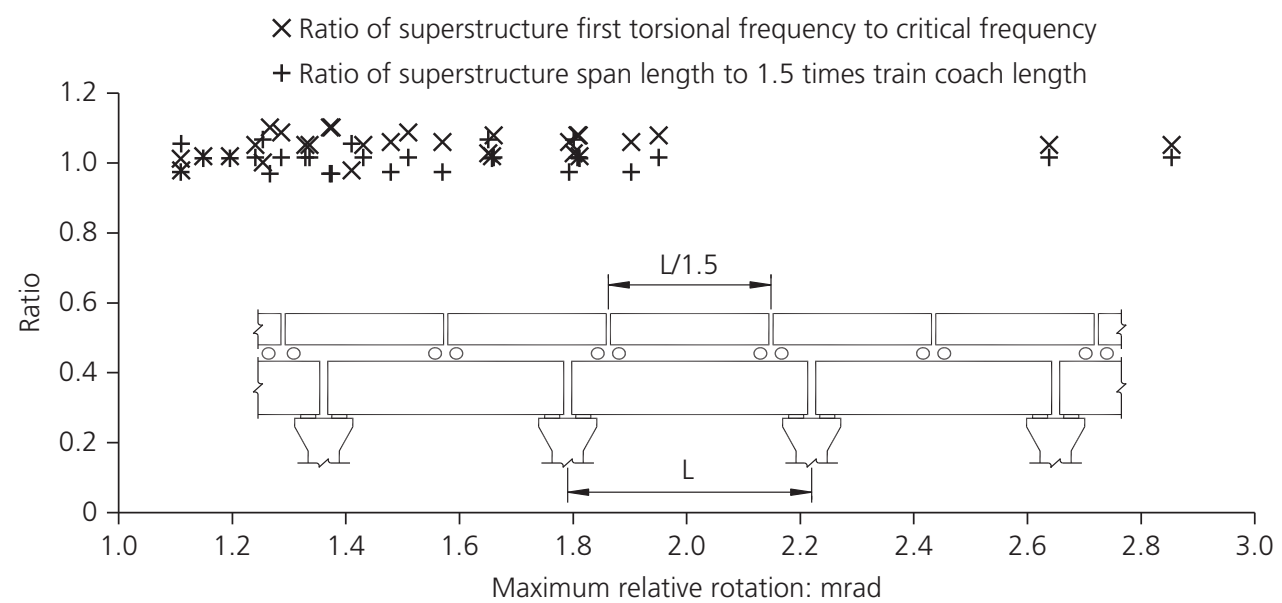

Figure 13. Relative rotations ( $\geq 1.1 \mathrm{mrad}$ ) as a function of frequency ratio and span/1.5 times coach length ratio

Time-history rotations of model 29 subjected to HSLM-A4 with a train speed of $110 \mathrm{~m} / \mathrm{s}$ are shown in Figure 14 for both girder top ends (points $\mathrm{A}$ and $\mathrm{B}$ ). The largest relative rotation was a result of point $B$ twisting counter-clockwise with a rotation of $1.22 \mathrm{mrad}$ and point A twisting clockwise with a rotation of $1.63 \mathrm{mrad}$ at $7.65 \mathrm{~s}$. At this moment, the middle of coach 9 was near the middle of the right span, allowing four axles to occupy this span while limiting two axles on the left span.

Additional analyses were performed for model 29 subjected to a static LM71 (BSI, 2003) plus an impact factor of 1.136 on one track over all spans before point A and a static HSLM-A4 with the first axle of the first coach reaching point $\mathrm{A}$. The static and dynamic responses due to these loads are summarised in Table 5, about which the following observations are made.

- Amplification due to resonance effects was large enough to make the dynamic rotational responses due to the lighter HSLM-A4 surpass the static rotational responses due to the heavier LM71 normally used for design purposes.

- Resonance effects were limited to the superstructure, including the bearings. The substructures in this study were not subject to resonance effects for the rotational mode because their first transverse frequencies $(0.671 \mathrm{~Hz}$ for model 29 and $0.566-2.456 \mathrm{~Hz}$ for all models) were very far from the superstructure first torsional frequencies (5.51 Hz for model 29 and 4.234-8.04 Hz for all models).

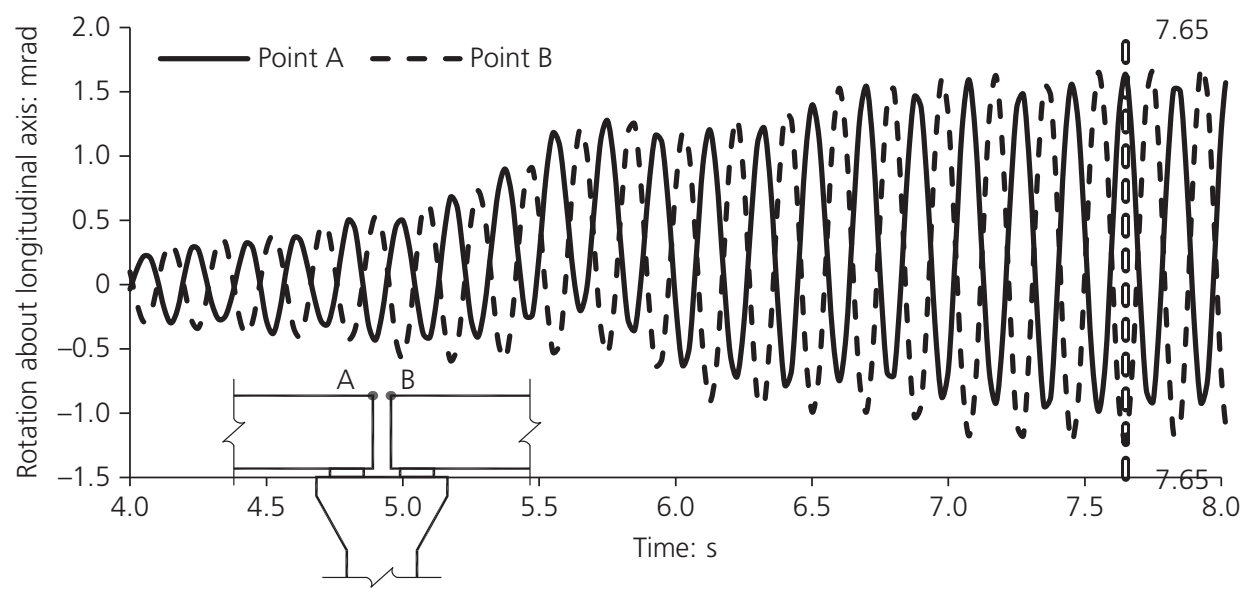

Figure 14. Time-history rotations of model 29 


\begin{tabular}{|c|c|c|c|c|}
\hline Response & $\begin{array}{l}\text { LM71 on } \\
\text { spans 1-19 }\end{array}$ & $\begin{array}{l}\text { Static HSLM-A4 } \\
\text { with first axle } \\
\text { reaching } \\
\text { point A }\end{array}$ & $\begin{array}{c}\text { Dynamic } \\
\text { HSLM-A4 at } \\
7.65 \mathrm{~s}\end{array}$ & $\begin{array}{c}\text { HSLM-A4 } \\
\text { dynamic/static } \\
\text { ratio }\end{array}$ \\
\hline Relative rotation about longitudinal axis over support 20: mrad & 0.83 & 0.24 & 2.85 & 11.88 \\
\hline Transverse displacement at top of column 20: mm & 7.67 & 2.21 & 2.15 & 0.97 \\
\hline Vertical deformation of bearing under span 19 on support 20: mm & $+0.57 /-1.56$ & $+0.13 /-0.49$ & $+2.66 /-2.97$ & $20.46 / 6.06$ \\
\hline
\end{tabular}

- In addition to torsional inertia of the girders, vertical deformations of the bearing pair also contributed to rotations of the superstructure. Amplification due to resonance effects on the bearings was large enough to make the dynamic responses due to the lighter HSLM-A4 surpass the static responses due to the heavier LM71. Note that a positive sign for the bearing vertical deformations in Table 5 is tension and a negative sign is compression. The superstructure self-weight was typically large enough to counteract uplift due to LM71, but net uplift was possible for model 29 subjected to resonance effects.

\subsection{Relative vertical displacements}

Relative vertical displacements between two consecutive decks have a direct impact on track profiles, which need to be controlled to avoid passenger comfort and riding stability concerns. Table 6 summarises the mean, median, maximum and minimum of the 10800 outputs, each classified by the key parameters. It was found that every mean and median of the outputs classified by all parameters was greater with an increase in magnitude of the parameters. No apparent correlation between the maximum and minimum outputs and the

Table 6. Statistical summary of relative vertical displacements classified by column height, span length, bearing layout and depth/span ratio

\begin{tabular}{|c|c|c|c|c|}
\hline \multirow[b]{2}{*}{ Parameter } & \multicolumn{4}{|c|}{ Relative vertical displacement: $\mathrm{mm}$} \\
\hline & Mean & Median & Maximum & Minimum \\
\hline \multicolumn{5}{|c|}{ Column height: m } \\
\hline 6 & 0.51 & 0.41 & 6.11 & 0.14 \\
\hline 8 & 0.63 & 0.48 & 5.22 & 0.15 \\
\hline 12.5 & 0.86 & 0.75 & 2.49 & 0.25 \\
\hline \multicolumn{5}{|c|}{ Span length: m } \\
\hline 26 & 0.62 & 0.49 & 3.77 & 0.15 \\
\hline 32 & 0.65 & 0.50 & 4.33 & 0.14 \\
\hline 38 & 0.73 & 0.55 & 6.11 & 0.18 \\
\hline \multicolumn{5}{|c|}{ Bearing layout: m } \\
\hline $4 \times 1.5$ & 0.42 & 0.38 & 2.20 & 0.14 \\
\hline $5 \times 2.5$ & 0.91 & 0.79 & 6.11 & 0.20 \\
\hline \multicolumn{5}{|c|}{ Depth/span ratio } \\
\hline $1 / 12$ & 0.66 & 0.51 & 5.22 & 0.14 \\
\hline $1 / 8$ & 0.68 & 0.52 & 6.11 & 0.16 \\
\hline
\end{tabular}

parameters was observed. The most sensitive parameter was the bearing layout and the least sensitive was the girder depth/span ratio.

For the 10800 outputs classified by train model, it was observed that the mean, median and minimum outputs were greater for HSLM-A9 and HSLM-A10 and the maximum outputs were higher for HSLM-A4 to HSLM-A6. For the 10800 outputs classified by train speed, the mean and maximum outputs were greater for train speeds of $45-75 \mathrm{~m} / \mathrm{s}$.

Out of the total 10800 outputs, $169(1.56 \%)$ exceeded the BS EN 1991-2:2003 (BSI, 2003) relative vertical displacement limit of $2 \mathrm{~mm}$. Out of these 169, 166 were for the longer bearing layout, 98 for a column height of $8 \mathrm{~m}, 87$ for the deeper girder and 71 for a span length of $38 \mathrm{~m}$.

A stacked histogram of the 169 outputs classified by train speed is shown in Figure 15. A high frequency and large outputs (especially greater than $5 \mathrm{~mm}$ ) were found for train speeds of 45 and $60 \mathrm{~m} / \mathrm{s}$.

The maximum outputs were plotted against the column's first longitudinal frequency and then classified by the two most sensitive parameters (i.e. bearing layout and column height), as shown in Figure 16. Discussions similar to those for Figure 9 apply to Figure 16.

The condition leading to large relative vertical displacements (especially those greater than $5 \mathrm{~mm}$ ) was identified for models 11, 23 and 24. Large outputs were found when the column's first longitudinal frequencies $(2.708,1.968$ and $2.048 \mathrm{~Hz}$ for models 11,23 and 24 , respectively) nearly matched the frequencies at the critical train characteristics $(2.857 \mathrm{~Hz}(60 \mathrm{~m} / \mathrm{s}$ train speed over $21 \mathrm{~m}$ HSLM-A4 coach length), $1.957 \mathrm{~Hz}$ (45 m/s train speed over $23 \mathrm{~m}$ HSLM-A6 coach length) and $2.143 \mathrm{~Hz}(45 \mathrm{~m} / \mathrm{s}$ train speed over $21 \mathrm{~m}$ HSLM-A4 coach length), respectively). Time-history vertical displacements of model 11 subjected to HSLM-A4 with a train speed of $60 \mathrm{~m} / \mathrm{s}$ are presented in Figure 17 for both girder top ends (points A and $\mathrm{B}$ ). The largest relative vertical displacement was a result of point B moving downwards with a vertical displacement of $2.7 \mathrm{~mm}$ and point A moving upwards with a vertical 


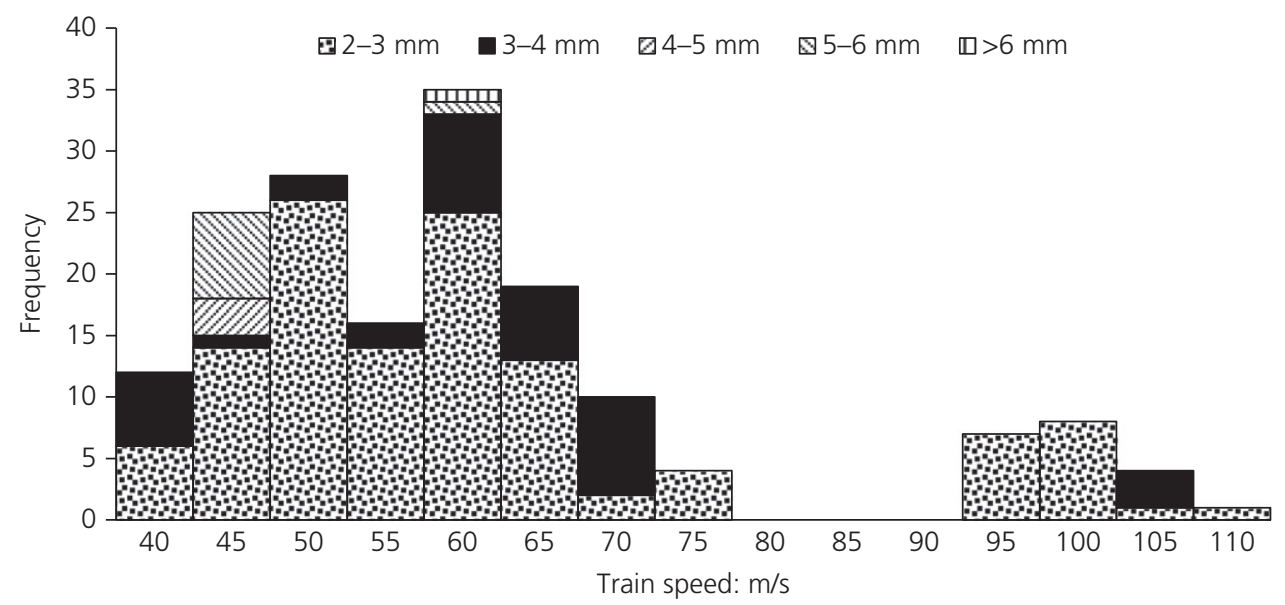

Figure 15. Histogram of relative vertical displacements $(\geq 2 \mathrm{~mm})$ classified by train speed

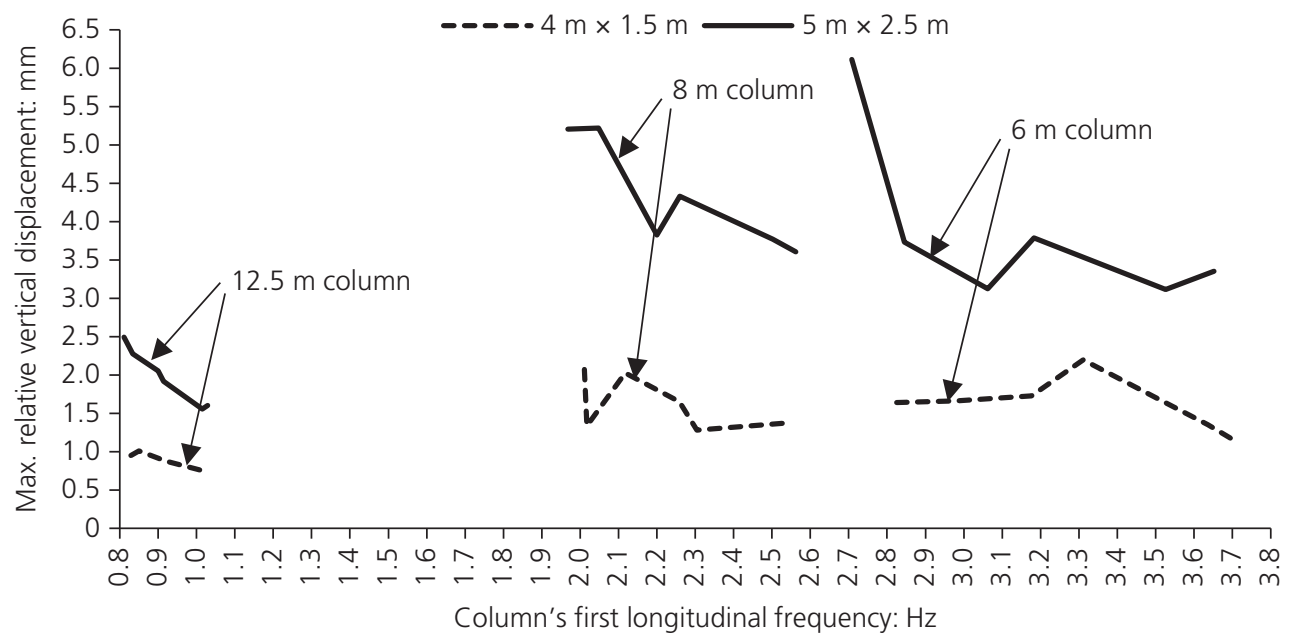

Figure 16. Maximum relative vertical displacements plotted against column first longitudinal frequency classified by column height and bearing layout

displacement of $3.4 \mathrm{~mm}$ at $18.875 \mathrm{~s}$. At this moment, the last two axles of the last coach were about to leave the last span, with the last axle $11.025 \mathrm{~m}$ away from the last abutment. The deformed geometry is similar to that shown in Figure 11, except that the deformed direction of support 19 was forwards and the deflection of span 19 was downwards.

Additional analyses were performed of model 11 subjected to a static LM71 (BSI, 2003) plus an impact factor of 1.105 on two tracks of the last span as well as a static HSLM-A4 with the same train position described above. A static HSLM-A4 with the last axle on the first bearing of the last span was also considered, as the position of HSLM-A4 at $18.875 \mathrm{~s}$ did not produce maximum static responses. The static and dynamic responses due to these loads are summarised in Table 7, about which the following observations were made.

- Amplification due to resonance effects was large enough to make the dynamic responses of the column due to the lighter HSLM-A4 surpass the static responses due to the heavier LM71 normally used for design purposes.

- The superstructure was not subject to resonance effects, partly as evident by a low dynamic-to-static ratio of reactions. However, large cyclic longitudinal and vertical displacements and rotations at the top of the column along with eccentric bearing seats induced cyclic vertical 


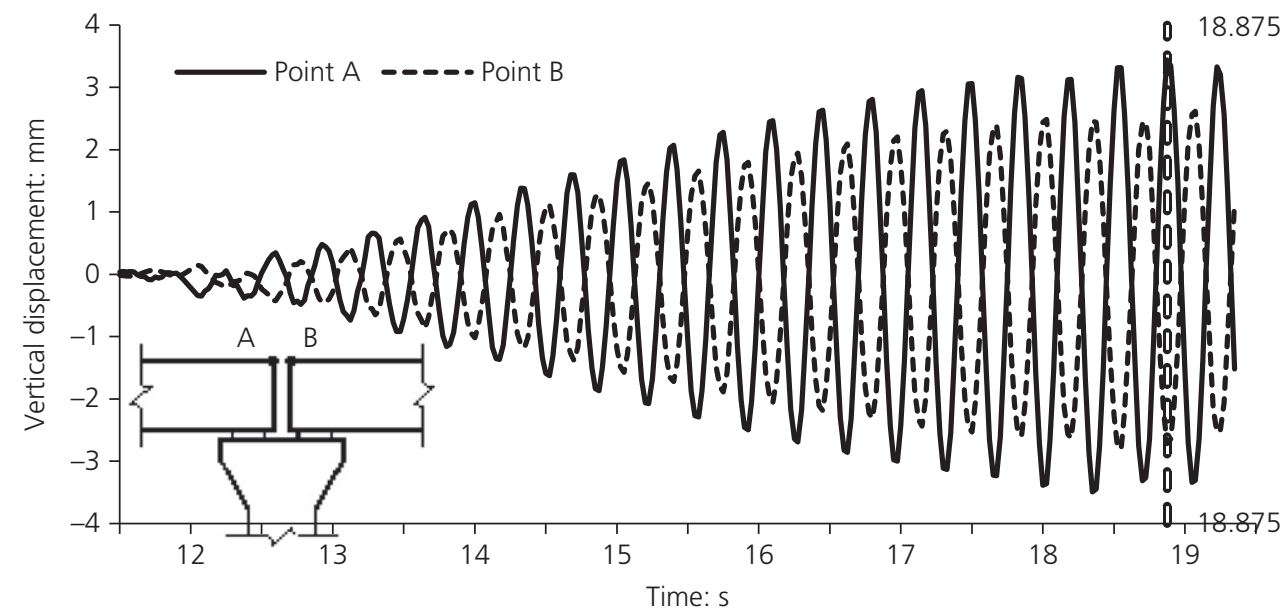

Figure 17. Time-history vertical displacements of model 11

Table 7. Summary of static and dynamic responses of model 11

\begin{tabular}{|c|c|c|c|c|c|}
\hline Response & $\begin{array}{c}2 \times \text { LM } 71 \\
\text { on span } \\
20\end{array}$ & $\begin{array}{c}\text { Static HSLM- } \\
\text { A4 with train } \\
\text { position at } \\
18.875 \mathrm{~s}\end{array}$ & $\begin{array}{c}\text { Static } \\
\text { HSLM-A4 } \\
\text { with last } \\
\text { axle at } \\
\text { support } 20\end{array}$ & $\begin{array}{c}\text { Dynamic } \\
\text { HSLM-A4 } \\
\text { at } 18.875 \mathrm{~s}\end{array}$ & $\begin{array}{c}\text { HSLM-A4 } \\
\text { dynamic/static } \\
\text { ratio }\end{array}$ \\
\hline Relative vertical displacement over support 20: mm & 1.27 & 0.01 & 0.28 & 6.11 & 21.82 \\
\hline Longitudinal displacement at top of column 20: mm & 1.56 & 0.04 & 0.29 & 11.44 & 39.45 \\
\hline Rotation about transverse axis at top of column 20: mrad & 0.42 & $9.5 \times 10^{-3}$ & 0.08 & 2.59 & 32.38 \\
\hline Mid-span deflection of span 20: mm & 9.10 & 0.42 & 1.34 & 8.08 & 6.03 \\
\hline Reaction of span 20 on support 20: kN & 3677.40 & 83.90 & 689.30 & 1178.50 & 1.71 \\
\hline
\end{tabular}

displacements of the bearing seats, which in turn vibrated the superstructure at the same column's first longitudinal frequency and caused additional dynamic mid-span deflection. In this case, the dynamic responses did not surpass the static responses.

\section{Conclusions}

The influences of four key parameters on relative longitudinal displacements, relative rotations about the longitudinal axis and relative vertical displacements were investigated through dynamic analyses of 36 numerical models. Statistical summaries from each numerical model for each of the three types of results have been provided and discussed in this paper. It was found that column height is generally the most influential parameter for relative longitudinal displacements. A weaker geometry against twist - collectively from a taller column height, narrower transverse bearing layout and deeper girder generally resulted in larger relative rotations. Bearing layout was generally the most sensitive parameter for relative vertical displacements.
The results of this study revealed that resonance effects are not only a significant problem for superstructures but also substructures when the stiffness of the substructure departs from being rigid. Similar to the resonance effects on superstructures when their vertical frequencies are near to or match the frequencies at critical train characteristics, resonance effects on substructures can also be encountered when their longitudinal frequencies are near to or match the frequencies at critical train characteristics. Large dynamic displacements at the top of substructures amplified by resonance effects can cause outof-phase motions of adjacent girders and induce relative displacements between two consecutive decks to surpass the design limits.

Most dynamic relative displacements and rotations were bound within the design limits typically used for design purposes. However, chances of relative displacements and rotations larger than the design limits by up to three times do exist. Regarding the relative longitudinal and vertical displacements, it was found that resonance effects from a near to exact match between the column's first longitudinal frequency and the 
frequency at critical train characteristics are the main contributor amplifying the responses. Peak effects were observed at moderate train speeds and for a longer longitudinal bearing layout. For relative rotations, it was observed that resonance effects from a near to exact match between the superstructure's first torsional natural frequency and the frequency at critical train characteristics, along with when a ratio of span to coach length is about 1.5 , were the main contributor amplifying the responses. Peak effects were observed for high train speeds, the tallest column height and the narrower transverse bearing layout. The presence of a span/coach length ratio of 1.5 for torsional resonance effects of relative rotations was not anticipated and was identified as an item to be investigated in future studies. Consideration of track-structure interaction was also identified as of interest in future work.

Based on the results of this study, dynamic relative displacements and rotations larger than the design limits are possible when the stiffness of the substructure departs from being rigid. In situations when flexible substructures cannot be avoided, it is recommended that dynamic analyses using numerical models with bearing, girder and column elements at their proper positions be performed to capture any excessive dynamic responses. Flexible substructures should not be treated as standard types but special bridge types (note that UIC 774-3R (UIC, 2001) recommends that it is not necessary to consider a detailed model of the substructure when standard bridges are considered, while substructures should be accurately modelled for special bridge types). Mitigation of any excessive dynamic responses may be done during the design process through adjustment of the four key parameters (column height, span length, bearing plan layout and ratio of depth to span length) studied in this work.

\section{Acknowledgement}

The author would like to thank his mentor and group leader, Pang Yen Lin, for his comments and support.

\section{REFERENCES}

Antolin P, Oliva J, Goicolea JM and Astiz MA (2011) Models for lateral dynamic interaction of high-speed trains and bridges. Proceedings of the 8th International Conference on Structural Dynamics, Leuven, Belgium (Guido de Roeck et al., (eds)), pp. 1172-1179.

BSI (2003) BS EN 1991-2:2003: Eurocode 1: Actions on structures. Traffic loads on bridges. BSI, London, UK.

CHSRA (California High-Speed Rail Authority) (2016) RFP Number HSR 14-32. Book III, Part A.1, Design Criteria Manual, Revision 3. CHSRA, Sacramento, CA, USA.

CSI (Computers \& Structures, Inc) (2017) Analysis Reference Manual for SAP2000, ETABS, SAFE and CSiBridge. Computers \& Structures, Inc, Berkeley, CA, USA.

Dias R, Goicolea JM, Gabaldon F et al. (2008) A study of the lateral dynamic behaviour of high speed railway viaducts and its effect on vehicle ride comfort and stability. IABMAS 2008 conference was hosted by Korea Bridge Design \& Engineering Research Center, Seoul National University, Seoul, Korea, pp. 724-735.

Domenech A, Martinez-Rodrigo MD, Romero A and Galvin P (2015) Soil structure interaction effects on the resonant response of railway bridges under high-speed traffic. International Journal of Rail Transportation 3(4): 201-214.

Goicolea JM and Antolin P (2011) Dynamic effects of railway traffic due to lateral motion in long viaducts with high Piers. Proceedings of the 3rd ECCOMAS Thematic Conference on Computational Methods in Structural Dynamics and Earthquake Engineering, Corfu, Greece.

He X, Wu T, Zou Y et al. (2017) Recent developments of high-speed railway bridges in China. Structure and Infrastructure Engineering 13(12): 1584-1595.

Luo X and Miyamoto T (2008) Examining the adequacy of the spectral intensity index for running safety assessment of railway vehicles during earthquakes. Proceedings of the 4th WCEE was organized by International Association for Earthquake Engineering (IAEE) and hosted by Chinese Association of Earthquake Engineering (CAEE).

NRA (National Railway Administration) (2015) TB 10621-2014: Code for design of high-speed railway. NRA, Beijing, China.

THSR (Taiwan High Speed Rail Corporation) (2005) Volume 9, Design Specifications. THSR, Taipei, Taiwan.

UIC (International Union of Railways) (2001) 774-3R: Track/bridge interaction. Recommendations for calculations, 2nd edn. UIC, Paris, France.

UIC (2009) 776-2: Design requirements for rail-bridges based on interaction phenomena between train, track and bridge, 2 nd edn. UIC, Paris, France.

Yan B, Dai GL and Hu N (2015) Recent development of design and construction of short span high-speed railway bridges in China. Engineering Structures 100: 707-717.

Yang YB, Yau JD and Wu YS (2004) Vehicle-Bridge Interaction Dynamics: with Applications to High-Speed Railways. World Scientific, Singapore.

\section{How can you contribute?}

To discuss this paper, please email up to 500 words to the editor at journals@ice.org.uk. Your contribution will be forwarded to the author(s) for a reply and, if considered appropriate by the editorial board, it will be published as discussion in a future issue of the journal.

Proceedings journals rely entirely on contributions from the civil engineering profession (and allied disciplines).

Information about how to submit your paper online is available at www.icevirtuallibrary.com/page/authors, where you will also find detailed author guidelines. 